\title{
Manejo do aleitamento materno de mães infectadas pelo vírus SARS-CoV-2: uma revisão integrativa
}

\author{
An approach to breastfeeding for mothers infected with the SARS-CoV-2: an integrative review \\ Manejo de la lactancia materna de madres infectadas con el virus SARS-CoV-2: una revisión integradora
}

\begin{abstract}
RESUMO
Objetivos: compreender as evidências disponiveis acerca da amamentação da mãe covid-19. Metodologia: Trata-se de uma revisão integrativa, feita três bases de dados, em três idiomas com três diferentes combinações de descritores em saúde. A busca resultou em 135 artigos, dos quais 6 atenderam os critérios de inclusão. Resultados: Não existem registros de presença de SARS-CoV-2 no leite humano até o momento. 0 aleitamento materno com medidas de prevenção é indicado.
\end{abstract}

DESCRITORES: Aleitamento Materno; Infecções por Coronavirus; Leite Humano; Pandemias.

\begin{abstract}
Objectives: to understand the evidence available regarding breastfeeding for mothers who test positive for Covid-19. Methodology: this article is an integrative review using three databases, in three languages with three different combinations of keywords related to health were applied. The search pulled up 135 articles, six of which met the criteria of inclusion. Results: the presence of SAR$\mathrm{S}-\mathrm{CoV}-2$ has not so far been registered in human breast milk. Breastfeeding is recommended, along with preventative measures. DESCRIPTORS: Breastfeeding; Coronavirus Infections; Milk, Human; Pandemics.
\end{abstract}

\section{RESUMEN}

Objectivos: comprender la evidencia disponible sobre la lactancia materna para una madre covid-19 positiva. Metodología: Esta es una revisión integradora, realizada en tres bases de datos, en tres idiomas, con tres combinaciones distintas de descriptores en salud. La búsqueda resultó en 135 artículos, de los cuales 6 cumplieron los criterios de inclusión. Resultados: No existen registros de la presencia de SARS-CoV-2 en la leche humana hasta el momiento. La lactancia materna con medidas protectivas es indicada. DESCRIPTORES: Lactancia Materna; Infecciones por Coronavirus; Leche Humana; Pandemias.

RECEBIDO EM: 22/05/2020 APROVADO EM: 23/05/2020

\section{Abilene do Nascimento Gouvêa}

Enfermeira, Doutoranda do programa de Pós Graduação em Ciências Médicas da UERJ. Mestre em Enfermagem. Especialista em Saúde da Mulher e Obstetrícia Social. Chefe da Unidade de Obstetrícia do Núcleo Perinatal do Hospital Universitário Pedro Ernesto/UERJ. Professora Auxiliar do Curso de Graduação em Enfermagem da Universidade Veiga de Almeida. https://orcid. org/0000-0002-3033-5069

\section{Talita Teresa do Carmo}

Acadêmica de Enfermagem da Universidade Veiga de Almeida. https://orcid.org/0000-0001-8864-1256

\section{INTRODUÇÃO}

들 m dezembro de 2019, a cidade de Wuhan na China notificou o primeiro caso de uma doença desconhecida que, posteriormente, seria denominada como COVID-19. A doença é causada por um novo tipo de Coronavírus, o SARS-Cov-2 ${ }^{(1)}$. Rapidamente a doença ultrapassou os limites de territórios chine- ses e, no dia 12 de março de 2020, a Organização Mundial de Saúde (OMS) declara o evento como pandêmico ${ }^{(2)}$. A pandemia, segundo dados da OMS, de 21 de maio de 2020, reúne 4.904.413 casos no mundo, sendo responsável por 323.412 mortes $^{(3)}$.

A transmissão do vírus ocorre através de gotículas e pode ser transmitida por uma pessoa infectada, sintomática ou não ${ }^{(4)}$, para outra que esteja a menos de um metro de distância. Ainda não existem evidências consistentes que permitam afirmar a possibilidade de transmissão por aerossóis, porém, precauções envolvendo procedimentos que envolvam a produção de aerossóis devem ser tomadas. Existem também evidências que permitem afirmar a transmissão do SARS-Cov-2 pelas fezes ${ }^{(5)}$.

A situação pandêmica mobilizou diversas entidades de saúde pelo mundo 
Mães com

suspeita ou

de COVID-19

deverão ser

orientadas quanto

prevenção da

transmissão, tanto

na convivência com

seu bebê, como

no ato de

amamentá-1o ${ }^{(7)}$. confirmação

às medidas de sional de saúde ${ }^{(7)}$. Diversas entidades de autoridade acadêmica advogam pela manutenção do aleitamento materno e destacam que os benefícios de se amamentar superam os riscos ${ }^{(8)}$.

Mães com suspeita ou confirmação de COVID-19 deverão ser orientadas quanto às medidas de prevenção da transmissão, tanto na convivência com seu bebê, como no ato de amamentá-lo ${ }^{(7)}$. Também se configura entre as opções, a possibilidade de ordenha do leite e oferta do leite em colher ou copinho, por um membro da família não infectado e fora da população de risco aumentado para desenvolvimento da Síndrome Respiratória Aguda Grave (SARS). No caso de extração leite com bomba, deverá ser orientada quando à higienização do equipamento ${ }^{(6-8)}$.

$\mathrm{O}$ presente estudo se justifica pela necessidade pungente de angariar informações e evidências científicas sobre a temática da amamentação no contexto pandêmico. Tendo como questão norteadora do trabalho: Quais as informações atuais de validade científica que permitem garantir a segurança do aleitamento materno frente à pandemia?

$\mathrm{O}$ artigo objetiva compreender as recentes discussões e evidências disponíveis acerca da amamentação da mãe COVID-19 positiva. Objetiva também investigar se os benefícios superam os riscos quando se trata de aleitamen- to materno no contexto específico de transmissão comunitária de COVID-19 pelo mundo.

\section{METODOLOGIA}

Foi realizada uma revisão integrativa, cuja modalidade de estudo é importante para o norteamento de tomada de decisão frente a condutas do cuidado dos profissionais de enfermagem e da saúde como um todo ${ }^{(9)}$.

Os artigos foram levantados no mês de maio de 2020 em três diferentes bases de dados, foram elas: Scientific Eletronic Library Online (SciELO), Biblioteca Virtual em Saúde (BVS) e PubMed.

A escolha pelos descritores foi feita em base nos Descritores em Ciências da Saúde (DeCS). Os descritores correspondentes foram escolhidos nos três idiomas: português, inglês e espanhol. A combinação dos descritores, utilizando a ferramenta de operador booleano "AND" estão expressas no seguinte Quadro 1. Os descritores estão representados em português, porém, é importante enfatizar que a busca foi realizada nas bases de dados escolhidas também com os descritores correspondentes em inglês e espanhol.

Ao total, foram rastreados 135 artigos. Após a remoção de artigos duplicados, havia 93 artigos. Foi feita uma pré análise, com leitura de resumos e de acordo com a não conformidade aos critérios de inclu-

\section{Quadro 1. Rastreamento de artigos. Rio de Janeiro, RJ, Brasil, 2020}

para melhor compreensão e combate à COVID-19(2). Tornou-se necessário um olhar para a amamentação e a possibilidade de transmissão do vírus pelo leite humano. Embora não haja evidências científicas sólidas até o momento, o leite humano não parece transmitir o vírus. Porém, a transmissão mãe-bebê é aumentada pelo contato próximo que o momento de amamentar promove ${ }^{(6)}$.

Sabe-se que o leite materno é a melhor fonte de alimentação para bebês e, no contexto do COVID-19, o ato de amamentar deverá ser uma escolha da mãe e família, com a orientação adequada de um profis-

\begin{tabular}{|l|c|c|}
\hline \multicolumn{1}{|c|}{ DESCRITORES } & BASE DE DADOS & $\begin{array}{c}\text { NÚMERO DE ARTIGOS } \\
\text { ENCONTRADOS }\end{array}$ \\
\hline \multirow{2}{*}{$\begin{array}{l}\text { "Infecção por Coronavírus" AND "Aleita- } \\
\text { mento Materno" }\end{array}$} & SciELO & 0 \\
\cline { 2 - 3 } & PubMed & 10 \\
\hline \multirow{3}{*}{$\begin{array}{l}\text { "Infecção por Coronavírus" AND "Leite } \\
\text { Humano" }\end{array}$} & BVS & 28 \\
\cline { 2 - 3 } & SciELO & 0 \\
\cline { 2 - 3 } & PubMed & 13 \\
\hline \multirow{2}{*}{ "Infecção por Coronavírus" AND "Lactação" } & BVS & 28 \\
\cline { 2 - 3 } & SciELO & 0 \\
\cline { 2 - 3 } & PubMed & 48 \\
\hline
\end{tabular}


Fluxograma 1. Seleção de artigos. Rio de Janeiro, RJ, Brasil, 2020

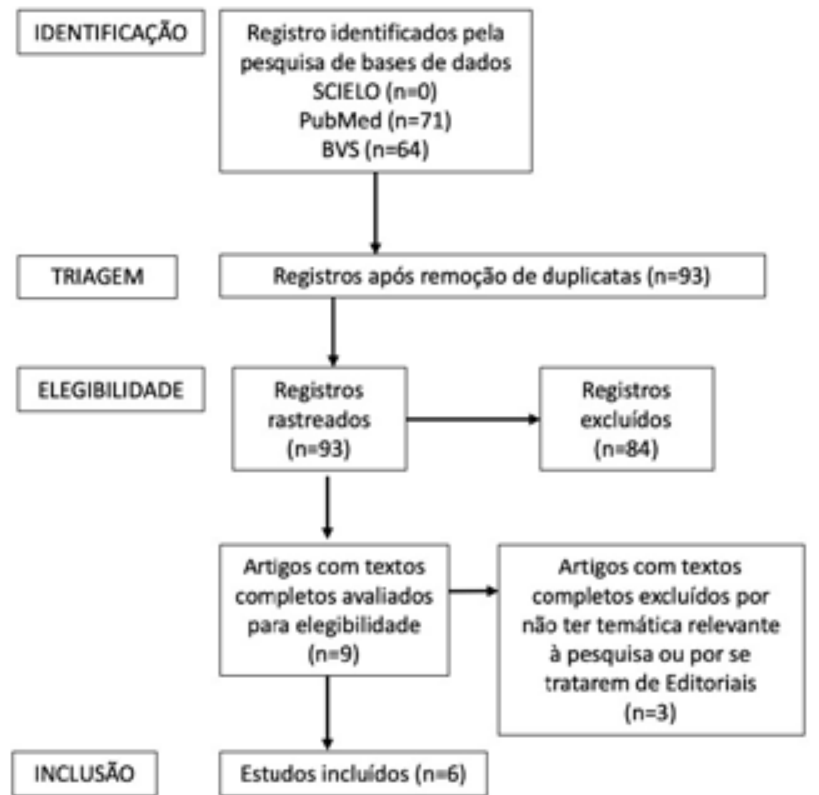

são, foram excluídos 84 artigos, restando 09 artigos para a leitura integral.

Os critérios de inclusão para compor essa revisão integrativa foram que para ser escolhido, o estudo deveria: estar disponível on-line gratuitamente; estar no formato de artigo científico; ser escrito em português, inglês ou espanhol, ter relevância ao tema e ter sido publicado no ano de 2020. Após minuciosa análise e aplicação dos critérios, 06 artigos foram selecionados.

\section{RESULTADOS}

$\mathrm{O}$ artigo foi construído com base nos guidelines da metodologia do Preferred Reporting Items for Systematic Reviews and Meta-Analyses (PRISMA). A seleção de artigos para composição da presente revisão integrativa foi organizada no Fluxograma 1.

Os seis artigos selecionados foram organizados no Quadro 2, onde estão apresentados os principais resultados de cada um dos estudos, de forma sucinta.

Quadro 2. Resultados. Rio de Janeiro, RJ, Brasil, 2020

\begin{tabular}{|c|c|c|c|c|}
\hline & $\begin{array}{l}\text { PERIÓDICO E ANO } \\
\text { DE PUBLICAÇÃOO }\end{array}$ & AUTORES & TÍTULO & PRINCIPAL RESULTADO \\
\hline Artigo 1 & The Lancet, 2020. & $\begin{array}{l}\text { Chen } \mathrm{H} \text {, Guo J, } \\
\text { Wang C et al. }\end{array}$ & $\begin{array}{l}\text { Clinical characteristics and intrauteri- } \\
\text { ne vertical transmission potential of } \\
\text { COVID-19 infection in nine pregnant } \\
\text { women: a retrospective review of me- } \\
\text { dical records. }\end{array}$ & $\begin{array}{l}\text { Amostras de leite materno de } \\
\text { seis pacientes Covid-19 posi- } \\
\text { tivas não apresentaram pre- } \\
\text { sença do vírus SARS-Cov-2 no } \\
\text { leite humano. }\end{array}$ \\
\hline Artigo 2 & $\begin{array}{l}\text { Breastfeeding } \\
\text { Medicine, } 2020 .\end{array}$ & $\begin{array}{l}\text { Salvatori G,De Rose DU, } \\
\text { Concato C et al. }\end{array}$ & $\begin{array}{l}\text { Managing COVID-19-Positive Mater- } \\
\text { nal-Infant Dyads: An Italian Experience. }\end{array}$ & $\begin{array}{l}\text { A transmissão do vírus SAR- } \\
\text { S-Cov-2 entre o binômio mãe } \\
\text { bebê parece estar melhor asso- } \\
\text { ciada à transmissão horizontal. }\end{array}$ \\
\hline Artigo 3 & $\begin{array}{l}\text { Italian Journal of } \\
\text { Pediatrics, } 2020 .\end{array}$ & $\begin{array}{l}\text { De Rose DU, Piersigilli F, } \\
\text { Ronchetti MP et al. }\end{array}$ & $\begin{array}{l}\text { Novel Coronavirus disease (COVID-19) } \\
\text { in newborns and infants: what we } \\
\text { know so far. }\end{array}$ & $\begin{array}{l}\text { A evidência disponivel não é su- } \\
\text { ficiente para descartar a possi- } \\
\text { bilidade da transmissão do vírus } \\
\text { pelo leite humano. }\end{array}$ \\
\hline Artigo 4 & $\begin{array}{l}\text { Journal of Perinatolo- } \\
\text { gy, } 2020 .\end{array}$ & $\begin{array}{l}\text { Mimouni F, Lakshmin- } \\
\text { rusimha S, Pearlman } \\
\text { SA et al. }\end{array}$ & $\begin{array}{l}\text { Perinatal aspects on the covid-19 } \\
\text { pandemic: a practical resource for pe- } \\
\text { rinatal-neonatal specialists }\end{array}$ & $\begin{array}{l}\text { A presença de SARS-Cov-2 no } \\
\text { leite humano não foi documen- } \\
\text { tada até o momento. }\end{array}$ \\
\hline Artigo 5 & $\begin{array}{l}\text { Pan American Journal } \\
\text { of Public Health, } \\
2020 .\end{array}$ & $\begin{array}{l}\text { Martins-Filho PR, San- } \\
\text { tos VS, Santos Jr HP. }\end{array}$ & $\begin{array}{l}\text { To breastfeed or not to breastfeed? } \\
\text { Lack of evidence on the presence of } \\
\text { SARS-CoV-2 in breastmilk of preg- } \\
\text { nant women with COVID-19. }\end{array}$ & $\begin{array}{l}\text { Não há consenso entre as insti- } \\
\text { tuições de saúde sobre a trans- } \\
\text { missão de SARS-Cov-2 pelo } \\
\text { leite materno. }\end{array}$ \\
\hline Artigo 6 & $\begin{array}{l}\text { Pan American Journal } \\
\text { of Public Health, } \\
2020 .\end{array}$ & $\begin{array}{l}\text { Duran } \mathrm{P} \text {, Berman } \mathrm{S} \text {, } \\
\text { Niermeyer } \mathrm{S} \text { et al. }\end{array}$ & $\begin{array}{l}\text { COVID-19 and newborn health: sys- } \\
\text { tematic review. }\end{array}$ & $\begin{array}{l}\text { Mães positivas para Covid-19 } \\
\text { não justifica suspensão da ama- } \\
\text { mentação. }\end{array}$ \\
\hline
\end{tabular}




\section{DISCUSSÃO}

Não foi documentado até o presente momento a presença do vírus SARS$-\mathrm{CoV}-2$ no leite materno ${ }^{(10)}$. O principal estudo, de notoriedade nos principais guidelines brasileiros e internacionais, traz a amostra de seis pacientes COVID-19 positivas no terceiro trimestre gestacional cujo leite humano analisado não apresentou a presença do vírus ${ }^{(11)}$. Outros estudos trazem a negativação, um deles reporta 30 amostras de leites analisadas ${ }^{(12)}$.

Embora os principais guidelines, como o do CDC, RCOG e WHO, usem esses estudos como base, é impossível afirmar até o momento que o leite materno não possa ser uma via de transmissão do vírus, uma vez que as evidências ainda sejam limitadas ${ }^{(13)}$. Porém, não existem dados suficientes para se contraindicar o aleitamento materno, os benefícios parecem superar os $\operatorname{riscos}^{(14)}$.

A temática é controversa e isso é refletido por condutas que diferem umas das outras. O National Health Comission of China recomenda o isolamento de recém-nascidos suspeitos e confirmados de COVID-19 em enfermarias de coorte por 14 dias. Essa conduta é criticada uma vez que pode levar a desfechos neonatais desfavoráveis para os casos suspeitos, em que não existe de fato a infecção pelo SARS-CoV-2(15).

Considerando o que parece ser consenso entre importantes instituições científicas de saúde materno infantil, é recomendado que a mãe infectada pelo vírus seja aconselhada a iniciar ou manter o aleitamento materno com algumas medidas de proteção para prevenir a transmissão mãe-bebê por gotículas, é indicado o uso de máscara, a higienização das mãos reforçada antes do contato com o bebê e o distanciamento de 2 metros ao dormir pelo tempo de 14 dias $^{(12-14)}$. A promoção da amamentação segue sendo benéfica. É importante sempre avaliar as drogas utilizadas pela mãe e avaliar se são compatíveis com a amamentação ${ }^{(12)}$.

Nas mães em que a COVID-19 se manifesta em formas mais graves e
Não foi

documentado até o

presente momento

a presença do vírus

SARS-CoV-2 no

leite materno ${ }^{(10)}$.

$O$ principal estudo,

de notoriedade

nos principais

guidelines

brasileiros e

internacionais,

traz a amostra

de seis pacientes

COVID-19 positivas

no terceiro trimestre

gestacional cujo leite

humano analisado

não apresentou a

presença do vírus ${ }^{(11)}$. ocorre a impossibilidade da amamentação, é preferível que se faça a ordenha do leite, atentando-se para a higiene das mãos e de bomba de extração de leite - caso seja utilizada ${ }^{(10,12)}$ - e a oferta do leite pode ser realizada por um terceiro, desde que saudável ${ }^{(14)}$. Quando esse cenário não for uma opção possível, a busca por um banco de leite humano surge como uma possibilidade ${ }^{(15)}$.

\section{CONCLUSÃO}

Embora não se possa afirmar que o leite materno esteja livre do vírus SARS-CoV-2 por conta de limitação de amostragem dos estudos disponíveis, não há nenhum dado, até o presente momento, que permita tender para a conclusão de que o vírus está presente no leite humano.

A opção por iniciar ou dar continuidade ao aleitamento materno, na ocasião da infecção materna pelo vírus, deverá ser uma decisão materna, em conjunto com a família e profissionais da saúde. As mulheres devem ser instruídas em favor da prática e orientadas quanto às medidas de proteção e possibilidades alternativas à oferta do seio.

Os benefícios do leite materno de mães infectadas superaram os riscos de optar por não ofertar esse leite, segundo o que trazem as evidências científicas até o momento. Nos casos nos quais se torna impraticável a ordenha e oferta ao bebê do leite da mãe, os bancos de leite humano surgem como possibilidade a ser considerada.

O conhecimento da temática ainda deixa muitas lacunas do conhecimento a serem preenchidas, sugere-se mais estudos, com amostragens em maior quantidade nos quais haja testagem da presença do vírus no leite humano. Seria benéfica a realização de estudos que tragam a taxa de transmissão horizontal entre mãe e bebês que amamentam.

Essa revisão apresentou limitações, por ser um tema atual e tra- 
tar-se de uma doença que surgiu há menos de seis meses. Porém, os da- dos trazidos são o reflexo do conhecimento existente sobre aleitamento em associação com a COVID-19 até o presente momento.

\section{REFERÊNCIAS}

1. World Health Organization. Reducing animal-human transmission of emerging pathogens [Internet]. Published 26 March 2020 [acesso em 20 mai 2020]. Disponivel em: https://www.who.int/health-topics/ coronavirus/who-recommendations-to-reduce-risk-of-transmission-of-emerging-pathogens-from-animals-to-humans-in-live-animal-markets.

2. World Health Organization. WHO announces COVID-19 outbreak a pandemic [Internet]. Published 12 March 2020 [acesso em 20 mai 2020]. Disponível em: http://www.euro.who.int/en/health-topics/ health-emergencies/coronavirus-covid-19/news/ news/2020/3/who-announces-covid-19-outbreak-a-pandemic.

3. World Health Organization. WHO Coronavirus Disease (COVID-19) Dashboard [Internet]. Updated 21 May 2020 [acesso em 21 mai 2020]. Disponível em: https://covid19.who.int/.

4. Caldas JP, Tavares M. Da emergência de um novo vírus humano à disseminação global de uma nova doença - Doença por Coronavírus 2019 [Internet]. Epidemiologia da Covid-19, 2020 [acesso em 21 mai 2020]. Disponível em: http://asset.youoncdn. com/ab296ab30c207ac641882479782c6c34/070b44658f5569888804a14826ae273c.pdf.

5. World Health Organization. Modes of transmission of virus causing COVID-19: implications for IPC precaution recommendations [Internet]. Published 29 March 2020 [acesso em 21 mai 2020]. Disponivel em: https://www.who.int/news-room/commentaries/ detail/modes-of-transmission-of-virus-causing-covid-19-implications-for-ipc-precaution-recommendations.

6. Royal College of Obstetricians and Gynaecologists. Coronavirus (COVID-19) Infection in Pregnancy. Information for healthcare professionals [Internet]. Published 13 May 2020 [acesso em 20 mai 2020]. Disponível em: https://www.rcog.org.uk/globalassets/ documents/guidelines/2020-05-13-coronavirus-covid-19-infection-in-pregnancy.pdf.

7. Centers for Disease Control and Prevention. Care for Breastfeeding Women [Internet]. Published 20 May 2020 [acesso em 21 mai 2020]. Disponível em: https://www.cdc.gov/coronavirus/2019-ncov/hcp/ care-for-breastfeeding-women.html.

8. Ministério da Saúde, Fundação Oswaldo Cruz, Rede Brasileira de Bancos de Leite Humano (BR). Recomendação Técnica n.o 01/20.170320. COVID-19 e Amamentação. Brasília (DF)/Rio de Janeiro (RJ): MS, Fio- cruz e RBBL, 2020.

9. Crosseti MGO. Revisão integrativa de pesquisa na enfermagem: o rigor científico que Ihe é exigido. Rev. Gaúcha de Enfermagem [Internet]. 2012 [acesso em 03 mai 2020]; 33(2). Disponível em: https://www. scielo.br/pdf/rgenf/v33n2/01.pdf.

10. Mimouni $F$, Lakshminrusimha $S$, Pearlman SA, Raju T, Gallagher PG, Mendlovic J. Perinatal aspects on the covid-19 pandemic: a practical resource for perinatal-neonatal specialists. Journal of Perinatology [Internet]. 2020 [acesso em 21 mai 2020]. Disponível em: https://www.nature.com/articles/s41372020-0665-6.

11. Chen $H$, Guo J, Wang C, Luo F, Yu X, Zhang W, Li J, Zhao D, Xu D, Gong Q, Liao J, Yang H, Hou W, Zhan Y. Clinical characteristics and intrauterine vertical transmission potential of COVID-19 infection in nine pregnant women: a retrospective review of medical records. The Lancet [Internet]. 2020 [acesso em 21 mai 2020]. Disponível em: https://www. thelancet.com/journals/lancet/article/PIIS01406736(20)30360-3/fulltext.

12. Salvatori G, Rose DU, Concato C, Alario D, Olivini N, Dotta A, Campana A. Managing COVID-19-Positive Maternal-Infant Dyads: An Italian Experience. Breastfeeding Medicine [Internet]. 2020 [acesso em 21 mai 2020]. Disponivel em: https://www.liebertpub.com/ doi/full/10.1089/bfm.2020.0095.

13. Rose DU, Piersigilli F, Ronchetti MP, Santisi A, Bersani I, Dotta A, Danhaive O, Auriti C. Novel Coronavirus disease (COVID-19) in newborns and infants: what we know so far. Italian Journal of Pediatrics [Internet]. 2020 [acesso em 21 mai 2020]. Disponível em: https://pubmed.ncbi.nlm.nih.gov/32349772.

14. Duran P, Berman $S$, Niermeyer $S$, Jaenisch T, Forster T, Leon RGP, Mucio B, Serruya S. COVID-19 and newborn health: systematic review. Pan American Journal of Public Health [Internet]. 2020 [acesso em 21 mai 2020]. Disponível em: https://iris.paho.org/ bitstream/handle/10665.2/52039/v44e542020.pd$\mathrm{f}$ ? sequence $=5$.

15. Martins-Filho PR, Santos VS, Santos Jr HP. To breastfeed or not to breastfeed? Lack of evidence on the presence of SARS-CoV-2 in breastmilk of pregnant women with COVID-19. Pan American Journal of Public Health [Internet]. 2020 [acesso em 21 mai 2020]. Disponivel em: https://iris.paho.org/handle/10665.2/52038. 